\title{
Trend of Final Energy Intensity Changes in Lao PDR
}

\author{
Khamphone Nanthavong ${ }^{1}$, Sengratry Kythavone ${ }^{2}$ and Kinnaleth Vongchanh ${ }^{3}$ \\ Faculty of Engineering, National University of Laos, Vientiane 01005, Lao PDR
}

Received: November 27, 2014 / Accepted: December 31, 2014 / Published: March 31, 2015.

\begin{abstract}
While being developed, Lao society and economy have gradually shifted from agricultural-based to service-industrial oriented one. As a result, final energy consumption has rapidly changed. This paper studied a trend of changes in final energy intensity by looking at sector-wide energy demand and shares in gross domestic products. It was found that intensity of total final energy consumption in Lao PDR (People's Democratic Republic) gradually decreased during the last decades. This was resulted of high stable economic growth and comparatively slow growth in energy demand. Furthermore, Lao economy still relays mainly on less-energy intensive economic sectors, such as services and traditional agriculture. Although energy intensities of the industry, transportation and services sectors continuously decreased, but have slowed down in recent years. Moreover, energy intensity of agricultural sector continues increasing. All these facts give a ground for thinking that in the future, when socio-economic development of the country will reach higher level, there will be more energy consuming activities, then energy demand will increase while economic growth will slow down, and therefore, energy intensity is to increase. Knowledge on trend of energy consumption changes would be useful for predicting energy demand and securing energy supply in the future.
\end{abstract}

Key words: Energy intensity, final energy, energy consumption.

\section{Introduction}

This study is to find out the root causes and trend of the changes in final energy consumption in Lao PDR (People's Democratic Republic), by looking at sector-wide energy demand behavior and its connection to economic growth for a period of 2000-2012.

Government of Lao PDR had set a Millennium Goal to shift country out of a status of the Least Developed Countries by 2020. Country's modernization and industrialization, and rural electrification as well have been considered among the key issues in development programs of Lao government $[1,2]$.

Above mentioned policies of government will lead to significant changes in term of energy supply and demand by the main economic sectors. Therefore, knowledge on sector-wide energy demand behavior is crucial for reliability in energy forecasting and planning.

Corresponding author: Khamphone Nanthavong, professor, Ph.D., research fields: renewable energy based standalone rural electrification system, solar thermal power plant with organic working fluid, rural energy supply, energy policies and energy efficiency. E-mail: khamphon@fe-nuol.edu.la.
Socio-economic development of Lao PDR has significantly increased since its opening up in late 1980 s, turning from centrally planned economy to free market mechanism oriented. As a result of socio-economic development, energy consumption of the country has also continuously increased, particularly since late 1990s. Total final energy demand of Lao PDR reached 2.5 MTOE (million tons of oil equivalent) in 2012, with an annual growth of 3\%-4\% in parallel with stable and rapid economic growth [3].

As observed from the sector-wide demand for Lao final energy during a period 2000-2012, residential sector accounted for the largest share and had decreasing trend (62\% in 2000 to $54 \%$ in 2012) (Table 1 [4, 5]). The second largest consumption was by transportation sector, increased share from $20 \%$ to $23 \%$ for the same period. Final energy consumption share by industrial sector for that period was almost doubled $(5 \%$ to $8 \%)$. Moreover, agriculture sector shared smallest final energy consumption, but it had the highest growth: grew from $0.23 \%$ in 2000 to $1.13 \%$ in 2012 (or increased almost five times). The share of 
commercial sector in total energy consumption remains nearly unchanged for this period and accounts for about $15 \%$ of country's total final energy consumption.

Lao GDP (gross domestic products) stably grew at a rate of 7\%-8\% per annum (constant price 2002), especially since late 1990s. GDP per capita at current market price increased almost triple for period 2005-2012, from 511 US\$ to 1,396 US\$ [4].

While developing, Lao society is moving from backward agrarian format toward modern service and industrial oriented one. This can be seen from the changes in GDP contribution shares by the economic sectors.

In 2012, agriculture sector contributed the largest share to GDP and had decreasing trend (54\% to $35 \%$ for 2000 and 2012, respectively) (Table 1). The second largest share in total GDP in 2012 contributed by industry and almost doubled of share in 2000 . The third largest contribution was shared by service sector, slightly increased from share in 2000 . Contribution by transportation remained nearly unchanged.

\section{Materials and Methods}

The study has sought a target to look into details of energy consumption in each main economic sectors, its connection to economic growth (GDP). The data on GDP were obtained from websites of Lao Statistics Bureau [4] and UNESCAP [5], while final energy consumption were obtained from Department of Energy Policy and Planning (MEM (Ministry of Energy and Mines)) [6].

\section{Results and Discussions}

Total FEI (final energy intensity) by the main activities gradually decreased from 449 TOE (tons of oil equivalent)/(million 2005 PPP (purchase power parity \$) in 2000 to $138 \mathrm{TOE} /($ million $2005 \mathrm{PPP} \$$ ) in 2012 (Fig. 1), or at decreasing rate of $-9 \%$ per annum (Table 1) [7]. This is, probably due to relatively fast economic growth (7\%-8\%) versus still slow growth in final energy demand (3\%-4\%) [1]. Furthermore, for this period, Lao economy had still been relaying on less energy-intensive sectors, such as traditional agriculture, light industry and commerce, which together contributed almost $93 \%$ share in GDP, but consumed just $24 \%$ of total final energy demand of the country (Table 1).

Obviously, by-sector FEIs have had decreasing trend for 2000-2012, except for AC (agriculture sector) (Fig. 1, Table 2). The decrease of FEIs was especially significant for 2000-2005 and slowed down during 2006-2012. Although FEI of AC is increasing, but due to the fact that GDP share by agriculture rapidly decreased (almost halted during 2000 and 2012, Table 1), while its energy demand share still relatively small and therefore, its contribution to total FEI will also be negligible small. Thus, decrease of FEC (final energy consumption) intensities was due contribution by the transportation, industrial and commercial sectors.

During 2000-2012, transportation sector accounted for the highest final energy intensity $(1,483$ TOE/million 2005 PPP\$ in 2000), probably due to the fact that there was dominance of vehicle for personal use and furthermore, old vehicles were still widely used. Transportation FEI quickly decreased to 538 TOE/(million 2005 PPP\$) in 2012 (about $-8 \%$ per annum), despite of rapid increase of vehicle population (at 18\% increasing rate for 2001-2011, [8]), but

Table 1 Sector-wide share of final energy demand and GDP.

\begin{tabular}{|c|c|c|c|c|}
\hline \multirow[b]{2}{*}{ Sectors } & \multicolumn{2}{|c|}{ Final energy consumption (\%) } & \multicolumn{2}{|c|}{ Shares in GDP (\%) } \\
\hline & 2000 & 2012 & 2000 & 2012 \\
\hline Industry & 4.5 & 8.2 & 17 & 31.2 \\
\hline Transport & 19.5 & 22.8 & 5.9 & 6.3 \\
\hline Services (commercial) & 13.6 & 14.3 & 24 & 37.1 \\
\hline Agriculture & 0.2 & 1.1 & 54 & 26 \\
\hline Residential & 62 & 54 & - & - \\
\hline
\end{tabular}




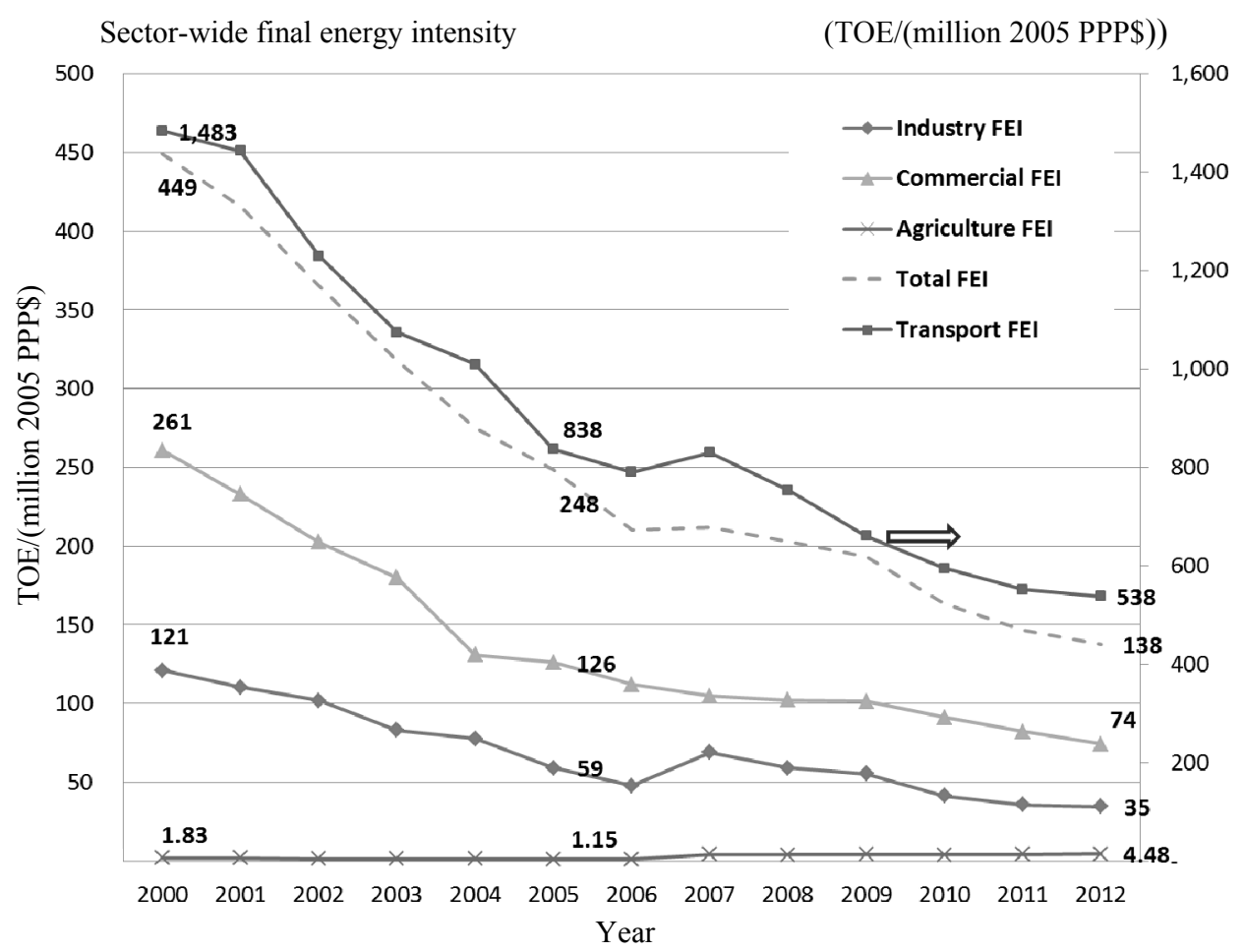

Fig. 1 Final energy consumption intensities.

Table 2 Trend of changes of energy consumption and GDP for a period 2000-2012.

\begin{tabular}{|c|c|c|c|c|c|}
\hline \multirow{2}{*}{ Sectors } & \multicolumn{2}{|c|}{ Final energy (\%) } & \multicolumn{2}{|c|}{ GDP (\%) } & \multirow{2}{*}{$\begin{array}{l}\text { Changes of EI } \\
\text { (energy intensity) } \\
(\%)\end{array}$} \\
\hline & Demand growth & By sector share growth & By sector growth & By sector share growth & \\
\hline Industry & 9 & 5.1 & 22 & 5.8 & -10 \\
\hline Transport & 5 & 1.3 & 15 & -0.1 & -8 \\
\hline Services & 5 & 0.4 & 16 & 1.0 & -10 \\
\hline Agriculture & 19 & 14.6 & 11 & -3.6 & 8 \\
\hline Residential & 3 & -1.2 & - & - & - \\
\hline Total & 4 & - & 1 & -4 & -9 \\
\hline
\end{tabular}

Source: author's compiled from data from Ministry of Energy and Mines.

perhaps, more productive use and increased new vehicle import. Moreover, demand on final energy by transportation sector grew at a rate of $6 \%$ per year for period 2000-2012, while GDP contribution by the sector grew faster, at $12 \%$, and as a result, the sector energy intensity is expected to continue decreasing. JICA (Japan International Cooperation Agency) study projected final energy demand share of transportation sector to increase to $29 \%$ by 2025 (BAU (business as usual)) [1].

Industrial and commercial sectors accounted for the highest decrease of final energy intensity during period
2000-2012, with annual average - $10 \%$ (Table 2). In the coming 10-15 years, these sectors are expected to grow intensively, in particular due to booming mining and construction industries, as well as rapidly growing commercial centers. According to recent projection by JICA, the industrial sector in Laos is assumed to have high real GDP growth and energy demand by the sector will rapidly increase (annual average 15\%) and expanding its share from $9 \%$ (2010) to $31 \%$ (2025), the highest shares, comparing to commercial (29.2\%) and residential (29.3\%) [3].

Energy demand by residential sector has the smallest 
annual growth (3\%) and its share decreased $-1.2 \%$ for a period of 2000-2012 and such trend will sustain up to 2025. JICA study predicted that, in the future, energy demand of residential sector shall continue growing, but its share will decrease to $29 \%$ by 2025 [1].

\section{Conclusions}

Booming economic development of the country has resulted in significant increase of energy demand. Continuous decrease of final energy consumption intensities for decades was due to fast economic growth and energy less intensive economic activities.

It was expected that, energy intensities to grow in the next decade, where the social-economic activities will reach higher levels of development and more energy consuming activities will occur.

The paper has taught some change behaviors knowledge on real energy demand changes behavior is essential for proper energy planning process and securing future sustainable energy supply. It is recommended that a careful study to find out the accurate correlation between energy intensity change behavior and economic growth would be necessarily important.

\section{References}

[1] Lao People's Democratic Republic. 2000. "Fighting Poverty through Human Resource Development, Rural Development and People's Participation." Presented at the 7th Roundtable Meeting, Vientiane, Lao PDR.

[2] Lao People's Democratic Republic. 2004. "NGPES (National Growth and Poverty Eradication Strategy)." Lao PDR.

[3] Japanese International Cooperation Agency. 2012. Data Collection Study on Energy Sector in Lao PDR. Final report.

[4] Lao Statistics Bureau. 2014. "Statistics Year Books 2014." MPI (Ministry of Planning and Investment). Accessed October 21, 2014. http://www.nsc.gov.la/.

[5] UNESCAP (United Nation Economic and Social Commission for Asia and the Pacific). 2014. "ESCAP Online Statistical Database." UNESCAP. Accessed June 23, 2014. http://www.unescap.org/stat/data/statdb/ DataExplorer.aspx.

[6] Department of Energy Policy and Planning. 2014. "Lao Energy Data for 1990-2012." Ministry of Energy and Mines.

[7] The World Bank. 2015. "PPP (Purchasing Power Parity) Conversion Factors of GDP (Local National Currency to International Dollar)." The World Bank. Assessed July 8, 2014. http://data.worldbank.org /indicator/PA.NUS.PPP.

[8] Japanese International Cooperation Agency. 2012. Basic Data Collection Study on Low-Emission Public Transport System in Lao PDR. Final report. 